\title{
A Study on the Evaluation of Woody Tree Vitality of Artificial Ground: Case Study of Seoullo 7017
}

\author{
Park, Seong-uk ${ }^{1}$ and Hong, Youn-Soon ${ }^{2 *}$ \\ ${ }^{1}$ Doctoral Program in Deparment of Landscape architecture, Hankyung University, Gyeonggi 17579, Korea \\ ${ }^{2}$ Professor, Deparment of Landscape architecture, Hankyung University, Gyeonggi 17579, Korea
}

\section{ABSTRACT}

Background and objective: This study examined, compared, and analyzed the tree vitality of the trees growing on the artificial ground of Seoullo 7017 that transformed the overpass that was to be demolished into a "sky garden" using portable tree pots.

Methods: Based on the summer season when the metabolic activity of plants is most active, this study measured the cambial electrical resistance in four directions(east, west, south and north), using the Shigometer (model OZ-93, Osmose) and compared the location and analysis of pots according to their means and standard errors.

Results: Meanwhile, according to the analysis, vitality was relatively superior in pots with a big diameter, trees planted individually than in groups, trees of the ramp section rather than the bridge section, and in the southwest direction of the cambium.

Conclusion: This study revealed the improper condition of the planting plan and implementation on the site, where various species of trees are displayed in a poor environment. Despite the significant assessment of the vitality of various trees introduced within Seoullo 7017 for the first time, this study is limited in that the data used were measured only once in summer. In this regard, it raised the need for continuous interest in and monitoring of a special plant environment and development of proper maintenance and management techniques, along with follow-up research on seasonal and temperature conditions, soil moisture and root development conditions to supplement this research.

Keywords: bridge section, ramp section, elevated road, overpass, shigometer

\section{Introduction}

Built on the foundation higher than the ground to avoid grade crossing with existing roads and promote limited traffic utility, overpasses have been constructed widely since the 1970s, which was the era of modernization in South Korea. However, there have been constant criticisms over the decline of safety due to facility deterioration and disturbance of the traffic flow and urban aesthetics. Thus, starting with the Seobinggo overpass in Yongsan-gu in 1980, 22 overpasses have been demolished as of 2020. This change in perception about overpasses indicates that the mechanistic paradigm of vehicular traffic efficiency has shifted to the value of a pedestrian-friendly city that attaches great importance to walking and green environments. In other words, as vehicle entry deterrence in the city and reinforcement of the walking range became the new norms, overpasses today have been reformed into an environment for walking and greens beyond just being demolished.

The case in which an urban car overpass is reborn as a new linear park in Korea is 'Seoullo 7017', which has been referred to as the 'Seoul Station overpass' by connecting the east and west of Seoul Station (Seoul Metropolitan City, 2017). Despite some concerns and controversies

Received: November 10, 2020, Revised: November 19, 2020, Accepted: December 10, 2020

First author: Park, Seong-uk, sanjeuks@hanmail.net, (D) https://orcid.org/0000-0002-7089-2652

*Corresponding author: Hong, Youn-Soon, yshong@hknu.ac.kr, (1) https://orcid.org/0000-0002-6260-7460 
among the stakeholders in its transformation process, Seoullo 7017 is established today as an attraction and a typical pedestrian environment in the heart of Seoul. However, to embody the concept of the prizewinner in the design competition, a great variety of trees are displayed in the pots above the artificial ground, raising doubts in terms of suitability and adaptability in a special environment. In other words, many issues raised regarding the planting environment of Seoullo 7017 that remodeled the existing overpass into a pedestrian green are related to the sustainability of trees in the artificial ground above the overpass. Thus, it is necessary to investigate and analyze the vitality of tree species today, which are stabilized 3 years after the completion of construction, from the perspective of an ex-post evaluation.

Accordingly, this study begins from the hypothesis that vitality among the great variety of trees at Seoullo 7017, which are being grown based on the tree pots in the special artificial ground of an overpass, will show a significant difference depending on detailed tree species, pot situation, and locational conditions. For demonstration, we empirically investigated the vitality of trees in summer when the growth of cambium, which shows the most active metabolic activity in the plant body, is most active and the cambial electrical resistance drops to the lowest Gao and Cha (2009) and comparatively analyzed this in various environmental conditions, thereby deriving implications for improvement of tree maintenance and similar projects in the future.

Results of literature review are as follows. Most studies on the planting environment in an artificial ground, which is the environment of this study, were limited to that formed by building an underground parking lot in an apartment housing complex. Kang et al. (2016) raised the problems of the artificial ground planting environment within an apartment complex and suggested improvement plans for greening. Choi (2017) also focused on the limitations of the artificial ground planting environment of an apartment housing complex and suggested improvement of such an environment. However, unlike an apartment housing complex divided by buildings and has limited landscaping trees within a certain scope, the subject of this study displays a great variety of trees based on the pot structure over the road. In this aspect, this study will diagnose the adaptability of various trees growing in an unusual environment and contribute to making improvements.

Meanwhile, as a result of reviewing exiting research methodologies to analyze the growth conditions of trees, the methodologies were generally classified into measuring the chlorophyll content or deducing tree vitality by measuring the cambial electrical resistance with the Shigometer. Studies using the Shigometer, which is the same tool used in this study, also made various approaches. Kim (1997), who diagnosed the damages of larch heart rots early on using the Shigometer, reports that the diagnosis accuracy rate from April to November when trees show most active growth is stable at around $88 \%$, especially in healthy trees. Moreover, Gao and Cha (2009) compared vitality measurement using the Shigometer and non-destructive inspection to manage big old trees at the cultural asset level and determined that using the Shigometer is most efficient in measuring relatively thin branches. As such, many studies using cambial electrical resistance compared the stress reactions of trees due to environmental changes and damages by blight and harmful insects or explored the relevance with physiological responses. On the other hand, there are some studies diagnosing the vitality differences in each situation by comparing electrical resistance among trees measured with the Shigometer. Hong et al. (2008) used this device to measure the electrical resistance of each plant within the same group of street trees planted at the same time, thereby revealing that tree vitality varies greatly depending on the locational condition such as soil properties, underplanting, tree protection facilities, and proximity to street furniture. This shows that measuring tree vitality with the Shigometer is still effective and powerful in indirectly inspecting the actual growth conditions of trees.

Objective details of the Seoullo 7017 formation process have been studied in various ways since the publication of its white paper Seoul Metropolitan City (2017) after completion. First, in terms of urban tourism, Choung(2018) demonstrated how urban greening in this environment contributed positively to urban regeneration in various aspects. Park et al. (2018) analyzed the walking tour characteristics changed by this environment through the spatial phase methodology of space syntax. Studies on the perception and recognition characteristics of this environment include 
Kim (2018), Park et al. (2018), Kim (2019), and Lee (2019), and there are also studies that raised issues regarding supplementation of plans such as Park and Lee (2019) and Yeom and Lee (2019).

Meanwhile, the only previous study that focused on the planting environment of Seoullo 7017 was Cha et al. (2020) which investigated and verified newly introduced plants a year after the opening of Seoullo 7017. That study has significance as it traced and analyzed the penetration of foreign trees focusing on grass species. However, there is no study that substantively, specifically, and empirically investigated and verified the growth conditions of trees as in this study.

\section{Research Methods}

\section{Site}

Seoullo 7017 has a dual meaning: a pedestrian road representing Seoul, and a path heading toward Seoul. '70' in 7017 refers to the year 1970 in which Seoul Station Overpass was built, and '17' refers to the year 2017 in which the park construction project was to be completed, as well as 17 pedestrian roads, and $17 \mathrm{~m}$ that indicates the height of the overpass. With the extension distance of $1,268 \mathrm{~m}$ and width of $18 \mathrm{~m}$, this overpass has been connecting Toegye-ro, Malli-dong, Cheongpa-ro, and Jungnim-dong. It was rated $\mathrm{D}$ in the precision safety diagnosis of Seoul in 2000 and 2006, and thus demolition and reconstruction were considered. Then in 2014, after undergoing over 600 public hearings such as site visit consultations of Seoul, meetings, discussions, and professional advice considering the traffic volume and surroundings, the city held the 'Seoul Station Overpass Idea Contest' among the general public and decided to regenerate the road that had been for vehicles in the past to the road for people. In the process of this policy change, the city referred to the successful case of New York's High Line, which is also mentioned in the white paper.

The design contest process for Seoullo 7017 is as follows. After collecting public opinions, the international design contest was held with the participation of 7 companies, ultimately selecting 'The Seoul Arboretum' by MVRDV's Winy Maas as the winner. The major details of his design plan are summarized as follows. First, he assimilated Seoul Station Overpass as a big tree and 17 ramps as branches, facilitating access to Seoul Station, Namsan Mountain, and buildings nearby with emphasis on connectivity to disconnected surrounding areas. For plantation, he arranged plants that can be grown in Seoul and artificial grounds in round pots according to the Korean names of each plant family in the order of 'ga, na, da (Korean alphabet)', thereby suggesting an open plant library where citizens can learn the names of plants as they walk through the overpass (Seoul Metropolitan City, 2017).

The basic and working designs for the Seoullo 7017 project were made from July 1, 2015 to February 27, 2016, and the construction began on April 18, 2016, and the place finally opened on May 20, 2017. According to related administrative documents, withered plants were fixed twice during the constructor's maintenance and repair period for 2 years, and the defect rate of the ramp section was $9.21 \%$, while that of the bridge section was more than 2.5 times higher at $23.55 \%$. After the maintenance and repair period, Civic Hub and Seoul urban regeneration social cooperative Seoullo 7017 signed an agreement for privately commissioned management called 'Walking Seoullo' on October 28, 2019.

Seoullo 7017, the study site, adopted the 'artificial ground greening system' using tree pots in the form of pots as shown in Fig. 1. There are total 645 pots in 66 types made of glass fiber reinforced concrete (GFRC), which is a relatively lightweight material. Pots with a diameter of $1.7 \mathrm{~m}$

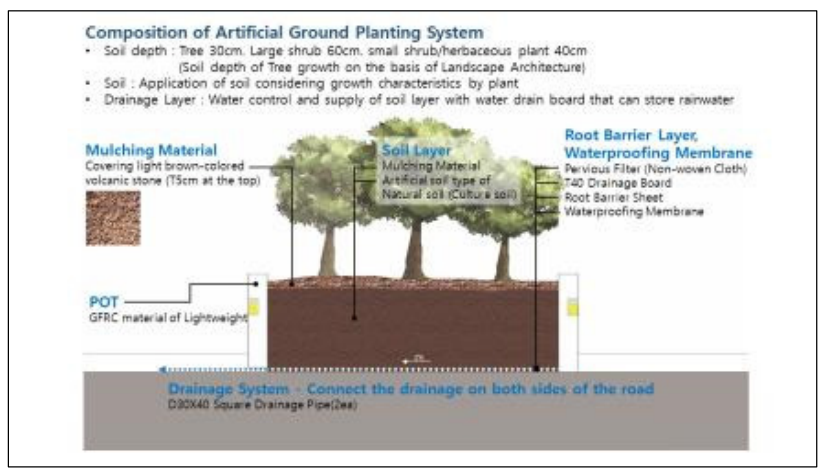

Fig. 1. section of artificial ground greening system (Seoul metropolitan city, 2017). 
or below were made and installed in a single round shape, but those with a diameter of $2.5 \mathrm{~m}$ or above were made separately in 4 pieces and then fixed with hardware and caulked on site. Soil depth required for plant growth was applied based on the 'Landscape Architecture Design Criteria (2013)' such as trees $(90 \mathrm{~cm})$, large shrubs $(60 \mathrm{~cm})$, small shrubs and herbaceous flowers $(40 \mathrm{~cm})$, and protected with mulching materials while securing the drainage system. As a result, total 24,085 trees in 50 families, 228 species were planted, with evergreens taking up at least 25\% (Seoul Metropolitan City, 2017).

\section{Field investigation overview}

As shown in (Fig. 2) the spatial scope of this study through prior investigation was approximately $814 \mathrm{~m}$ of the overpass section of Seoullo 7017 from the Malli-dong ramp to the Toegye-ro ramp. Approximately 80 species of trees are planted in total 12 different types of round tree pots such as 3 types in $126 \mathrm{~m}$ of the ramp structure retaining wall and 9 types in the $686 \mathrm{~m}$ bridge section. Thus, it is a key site that is suitable for comparative analysis of relative vitality depending on tree type and location. This study prepared the field questionnaire by receiving as-built drawings and tree volume tables from the operating organization of 'Walking Seoullo', and the content was specified with the cooperation of the constructor's field representative. Moreover, the content was confirmed and investigated with the participation of the field representative to prevent redundancies and omissions.

It was found that total 25 families, 80 species, 543 trees are currently growing there, and this study excluded trees that were withered or that have thin trunks and no cambium and thus cannot be measured. There were 7 withered tree species such as Magnolia X loebneri 'Wildcat', Magnolia 'Vulcan', Magnolia sieboldii, Magnolia 'Iolanthe', Magnolia zenii W.C.Cheng, Quercus dentata, and Chamaecyparis pisifera 'Filifera Aurea', and 2 species without cambium and thus that cannot be measured such as Aquifoliaceae Ilex crenata Thunb and Phyllostachys bambusoides Siebold $\&$ Zucc. Thus, the subjects were reduced to 71 species, 451 trees. But since complete enumeration was not feasible, we inspected the trees ledger with the field representative and determined the similarities such as plantation and transplantation time, standards, growing conditions, and maintenance, after which we selected 71 trees of the main species with relatively poor growth through visual examination.

Field investigation was conducted from 10:00 a.m. to 4:00 p.m. on July 27, 2020. Cambial electrical resistance was measured with the attendance of the field representative.

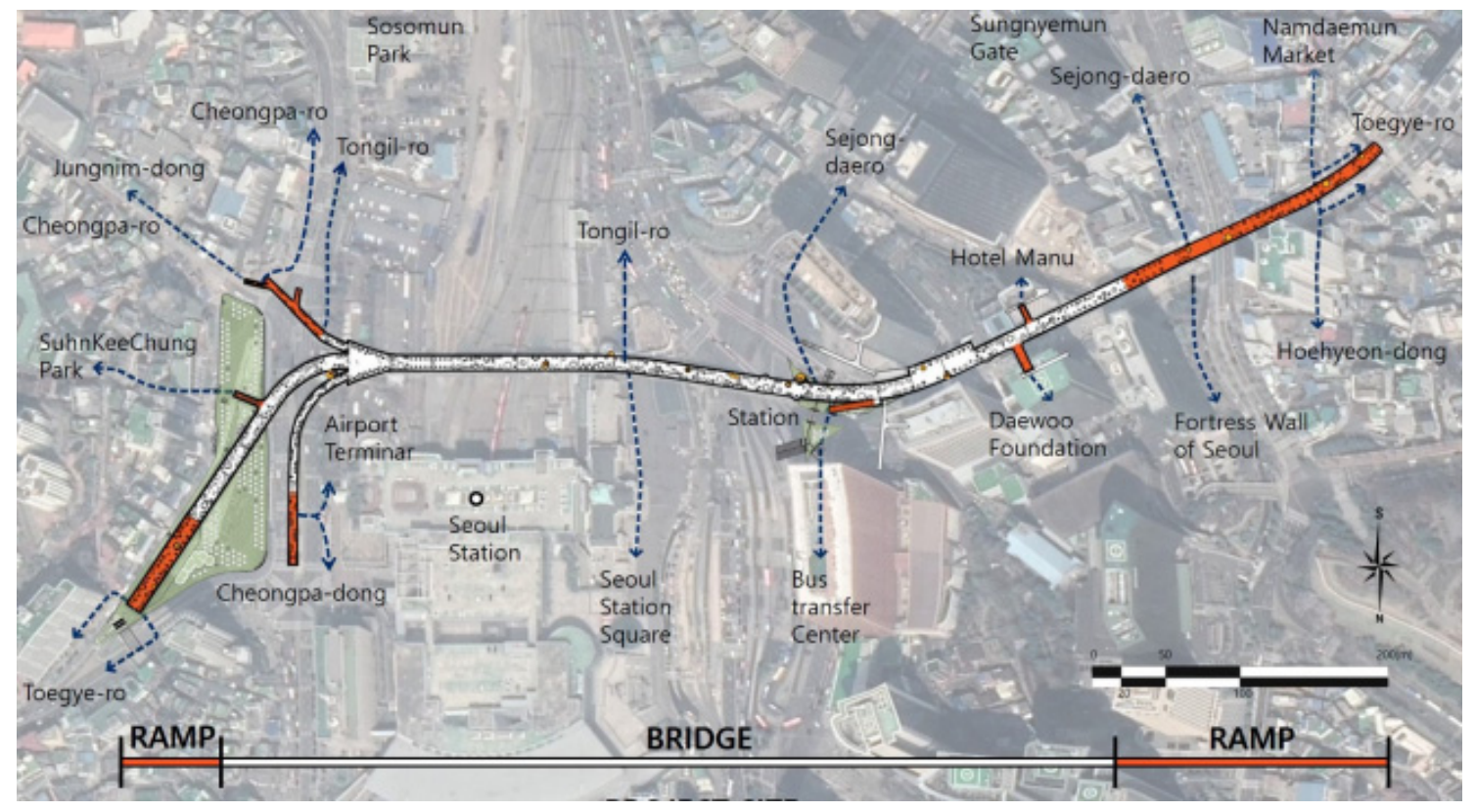

Flg. 2. research site. 
The investigation was conducted by 3 investigators with experience in handling the Shigometer. There was a drizzle on the day of the investigation, and the temperature was $24.8^{\circ} \mathrm{C}$, precipitation $1.5 \mathrm{~mm}$, humidity $88 \%$, and wind speed $10.8 \mathrm{~km} / \mathrm{h}$ northeast.

Cambial electrical resistance was measured using a portable field ohmmeter (Shigometer, model OZ-93, Osmose) based on the same method used in a previous study by Ha (2000). It was measured $1.2 \mathrm{~m}$ above the ground line (G.L.) in four cardinal points (north, south, east, and west), and the mean was extracted to reduce errors by entity. The needle electrodes are placed in a vertical direction and pushed into the bark until the wood is touched. When the number on the ohmmeter is stable, that value is used as the cambial electrical resistance of the tree. To compare cambial electrical resistance and tree vitality, we referred to previous studies by Kim (1997), Ha (2001), and Gao and Cha (2009), classifying the trees into relatively healthy trees (4-13k $\Omega$ ), relatively unhealthy cambium (14k $\Omega$ and higher), dying trees (20k $\Omega$ and higher), and dead trees (40-50k $\Omega$ and higher).

\section{Results and Discussion}

\section{Comparison by section and planted tree species}

The results of reviewing tree vitality of the main species by locational condition can be summarized as follows. First, the mean of 17 main trees of each species in the retaining wall section, which is the entry ramp, was $8.19 \mathrm{k} \Omega$, showing relatively higher vitality than the bridge section that showed the mean of $10.33 \mathrm{k} \Omega$. Even though the tree species in the retaining wall section were generally healthier than the sky garden on the bridge, there were some trees with low vitality due to relatively higher electrical resistance. Sciadopitys verticillata (Thunb.) Siebold \& Zucc. showed 13.00k 2 , Acer buergerianum Miq. showed $10.58 \mathrm{k} \Omega$, Acer palmatum showed $10.13 \mathrm{k} \Omega$, Acer triflorum showed $16.98 \mathrm{k} \Omega$, and Acer palmatum var. sanguineum Nakai showed $10.43 \mathrm{k} \Omega$. This is remarkably different from the trees showing single-digit figures in the same section, such as Zelkoba serrata with $3.80 \mathrm{k} \Omega$, Metasequoia glyp- tostroboides with $4.20 \mathrm{k} \Omega$, and Diospyros kaki Thunb with $5.58 \mathrm{k} \Omega$, showing that not only location but also the tree species factor is intervening.

Meanwhile, as a result of investigating 54 trees of the main species planted on the bridge over the road, the mean was $10.33 \mathrm{k} \Omega$, showing average vitality, but the following trees showed below-average vitality: Koelreuteria paniculata with $12.88 \mathrm{k} \Omega$, Chionanthus retusus Lindl. \& Paxton with $11.28 \mathrm{k} \Omega$, Lagerstroemia indica with $16.73 \mathrm{k} \Omega$, Pinus densiflora Siebold \& Zucc. with $11.85 \mathrm{k} \Omega$, Betula platyphylla var. japonica with $17.60 \mathrm{k} \Omega$, Prunus glandulosa $f$. sinensis with $14.58 \mathrm{k} \Omega$, Prunus sargentii with $13.60 \mathrm{k} \Omega$, Crataegus pinnatifida var. partita with $14.88 \mathrm{k} \Omega$, Juniperus rigida Siebold \& Zucc. var. cispidatus Pshenn. with $16.50 \mathrm{k} \Omega$, and Juniperus communis 'Gold Cone' with $18.05 \mathrm{k} \Omega$. In particular, Stewartia pseudocamellia Maxim. showed 21.68k $\Omega$ andThuja occidentalis L. showed $21.48 \mathrm{k} \Omega$, exceeding $20 \mathrm{k} \Omega$, which is the standard for vitality of a dying tree.

In sum, the trees planted in the ramp section generally showed superior vitality than those in the bridge section. By species, the vitality of Zelkoba serrata in the ramp section was highest with $3.80 \mathrm{k} \Omega$, and Cornus florida in the bridge section was highest with $3.43 \mathrm{k} \Omega$. However, even in the ramp section, Sciadopitys verticillata (Thunb.) Siebold \& Zucc., Acer buergerianum Miq., Acer palmatum, Acer triflorum, and Acer palmatum var. sanguineum Nakai showed relatively poor vitality with $10.13-16.98 \mathrm{k} \Omega$, whereas Diospyros kaki Thunb, Taxodium distichum, Metasequoia glyptostroboides, Zelkoba serrata, Acer pictum subsp. mono (Maxim.) Ohashi, Aesculus turbinata Blume, and Sophora japonica showed relatively fine vitality with $3.80-5.58 \mathrm{k} \Omega$. In sum, Acer triflorum was the only species in the ramp section that exceeded $14 \mathrm{k} \Omega$, the standard for vitality of an unhealthy tree, but there were 8 species in the bridge section. This is in line with the implications of Cha and $\mathrm{Na}$ (1993) comparing the electrical resistance of street trees with no abnormalities on the exterior in Suwon and Seoul in August, which is about the same time as this study. In other words, the research reported that the street trees of Seoul, which suffer more environmental stress such as air pollution and congestion, showed much higher cambial electrical resistance than the street trees of Suwon. This study showed that there is great- 
er environmental interference and disturbance in the bridge section of the overpass that is more open in the air than the ramp section. Table 1 . shows the trees exceeding $14 \mathrm{k} \Omega$, the standard for electrical resistance of unhealthy trees.

The results of comparing tree vitality by family in the conditions of 9 families planted in the bridge section and 14 families planted in the ramp section are as follows (Table 2). First, those in the ramp section showed high vitality, with Diospyros showing $5.58 \mathrm{k} \Omega$, Cinnamomum showing $4.20 \mathrm{k} \Omega$, Ulmus showing $5.44 \mathrm{k} \Omega$, and Aesculus

Table 1. tree vitality of unhealthy species

\begin{tabular}{|c|c|c|c|c|c|c|c|c|c|c|c|c|}
\hline \multirow{2}{*}{ section } & \multirow{2}{*}{ scientific name } & \multirow{2}{*}{ tree scale } & \multirow{2}{*}{ quantity } & \multicolumn{4}{|c|}{ direction $(k \Omega)$} & \multirow{2}{*}{$\begin{array}{l}\text { Average } \\
(\mathrm{k} \Omega)\end{array}$} & \multirow{2}{*}{ SD } & \multicolumn{2}{|c|}{ Tree Pots } & \multirow{2}{*}{$\begin{array}{l}\text { planting } \\
\text { pattern }\end{array}$} \\
\hline & & & & East & West & South & North & & & type & $\mathrm{D} \times \mathrm{H}(\mathrm{m})$ & \\
\hline ramp & Acer triflorum & H4.0xR18 & 3 & 18.20 & 16.60 & 14.20 & 18.90 & 16.98 & 1.81 & B & $1.7 \times 0.45$ & single \\
\hline \multirow{7}{*}{ bridge } & Lagerstroemiaindica & $\mathrm{H} 2.0 \times \mathrm{x} 18$ & 9 & 19.30 & 16.90 & 15.70 & 15.00 & 16.73 & 1.63 & G & $2.5 \times 0.95$ & 3-gathering \\
\hline & Prunus glandulosaf. sinensis) & $\mathrm{H} 3.5 \times \mathrm{x} 12$ & 2 & 15.00 & 17.00 & 12.80 & 13.50 & 14.58 & 1.61 & $\mathrm{E}$ & $1.7 \times 0.95$ & single \\
\hline & Crataegus pinnatifida var. partita & $\mathrm{H} 2.5 \times \mathrm{R} 10$ & 3 & 13.80 & 15.80 & 15.30 & 14.60 & 14.88 & 0.75 & G & $2.5 \times 0.95$ & 3-gathering \\
\hline & $\begin{array}{l}\text { Stewartia pseudocamellia } \\
\text { Maxim.) }\end{array}$ & $\mathrm{H} 2.5 \times \mathrm{x} 10$ & 17 & 23.90 & 22.20 & 19.80 & 20.80 & 21.68 & 1.54 & $\mathrm{E}$ & $1.7 \times 0.95$ & $\begin{array}{l}\text { 3-gathering \& } \\
\text { single }\end{array}$ \\
\hline & Koelreuteria paniculata & $\mathrm{H} 2.0 \times \mathrm{W} 1.0$ & 1 & 17.30 & 12.80 & 14.60 & 21.30 & 16.50 & 3.20 & $\mathrm{D}$ & $1.24 \times 0.95$ & single \\
\hline & Thuja occidentalis L. & $\mathrm{H} 3.0 \times \mathrm{W} 2.0$ & 5 & 24.10 & 14.70 & 17.30 & 29.80 & 21.48 & 5.91 & $\mathrm{D}$ & $1.24 \times 0.95$ & $\begin{array}{l}\text { 3-gathering \& } \\
\text { single }\end{array}$ \\
\hline & Juniperus communis 'Gold Cone' & $\mathrm{H} 1.2 \times \mathrm{W} 0.5$ & 11 & 21.00 & 18.90 & 14.30 & 18.00 & 18.05 & 2.42 & $\mathrm{E}$ & $1.7 \times 0.95$ & 5,3--gathering \\
\hline
\end{tabular}

Table 2. comparison of tree vitality by species

\begin{tabular}{|c|c|c|c|c|c|c|c|}
\hline section & species & tree quantity & East(k $\mathrm{k}$ ) & West(kß) & South(k8) & North(k8) & Average $(\mathrm{k} \Omega)$ \\
\hline \multirow{9}{*}{ ramp } & Rhamnus & 7 & 8.90 & 11.00 & 8.80 & 6.00 & 8.68 \\
\hline & Diospyros & 6 & 6.00 & 5.00 & 6.20 & 5.10 & 5.58 \\
\hline & Cercidiphyllum & 11 & 7.20 & 11.20 & 5.80 & 7.10 & 7.83 \\
\hline & Cryptomeria & 5 & 9.30 & 7.20 & 11.70 & 8.50 & 9.18 \\
\hline & Cinnamomum & 2 & 3.90 & 4.60 & 4.10 & 4.20 & 4.20 \\
\hline & Ulmus & 12 & 5.95 & 4.60 & 6.10 & 5.10 & 5.44 \\
\hline & Acer & 21 & 11.00 & 10.17 & 9.03 & 11.65 & 10.46 \\
\hline & Aesculus & 5 & 5.60 & 4.60 & 6.50 & 5.20 & 5.48 \\
\hline & Leguminosae & 7 & 7.65 & 8.05 & 8.35 & 6.80 & 7.71 \\
\hline \multirow{14}{*}{ bridge } & Styrax & 9 & 7.65 & 8.05 & 8.35 & 6.80 & 7.71 \\
\hline & Magnolia & 27 & 8.97 & 8.97 & 9.30 & 9.73 & 9.24 \\
\hline & Sapindus & 6 & 13.80 & 13.60 & 12.10 & 12.00 & 12.88 \\
\hline & Fraxinus & 20 & 10.35 & 10.30 & 10.05 & 10.15 & 10.21 \\
\hline & Lythrum & 9 & 19.30 & 16.90 & 15.70 & 15.00 & 16.73 \\
\hline & Pinus & 23 & 8.98 & 9.54 & 8.38 & 8.50 & 8.85 \\
\hline & Ginkgo & 2 & 4.50 & 4.80 & 4.00 & 4.00 & 4.33 \\
\hline & Betula & 37 & 20.40 & 14.30 & 11.20 & 10.85 & 14.19 \\
\hline & Rosa & 46 & 10.69 & 11.05 & 11.23 & 10.60 & 10.89 \\
\hline & Taxus & 14 & 9.40 & 9.60 & 8.30 & 13.80 & 10.28 \\
\hline & Camellia & 17 & 23.90 & 22.20 & 19.80 & 20.80 & 21.68 \\
\hline & Quercus & 13 & 8.52 & 7.92 & 7.70 & 7.37 & 7.88 \\
\hline & Thuja & 54 & 13.54 & 11.18 & 12.00 & 13.91 & 12.66 \\
\hline & Cornus & 52 & 6.44 & 5.94 & 6.22 & 5.78 & 6.10 \\
\hline
\end{tabular}


showing $5.48 \mathrm{k} \Omega$, whereas Rhammus showed $8.68 \mathrm{k} \Omega$, Taxodium showed $9.18 \mathrm{k} \Omega$, and Acer showed $10.46 \mathrm{k} \Omega$ with relatively poor vitality. On the other hand, many tree species showed poor vitality in the bridge section compared to the ramp section, such as Sapindus with $12.88 \mathrm{k} \Omega$, Fraxinus with $10.21 \mathrm{k} \Omega$, Lythrum with $16.73 \mathrm{k} \Omega$, Betula with $14.16 \mathrm{k} \Omega$, Rosa with $10.89 \mathrm{k} \Omega$, Taxus with $10.28 \mathrm{k} \Omega$, and Thuja with $12.66 \mathrm{k} \Omega$. In particular, Camellia showed $21.68 \mathrm{k} \Omega$, which is about the vitality level of a dying tree. On the other hand, even in the bridge section, Ginkgo showed $4.33 \mathrm{k} \Omega$ and Cornus showed $6.10 \mathrm{k} \Omega$, proving to have high vitality.

These results typically reveal the relative vitality differences of each tree type at the point of measurement, as shown in the study by Ha (2000) that cross-correlated the vitality of Zelkova serrata, Acer palmatum, and Abies firma in the same space to demonstrate the hypothesis that electrical resistance of each tree has its 'own unique value' and varies depending on growth period or speed, and thus can be the vitality index of trees. Therefore, this result must be determined in line with detailed location environment and planting method that will be mentioned later, not as an absolute index.

\section{Comparison by type of tree pot and planting method}

The planting infrastructure of Seoullo 7017 is based on round tree pots made of high-strength and lightweight materials in various sizes. There are total 645 pots in 66 types including the ones for herbaceous flowers, but trees can be planted in only 12 types including the bench-combined type, applied to total 260 pots in the research site. The results of analyzing 221 pots in proportion to the type of tree pots are as follows (Table 3).

Tree pots in Types A, B, and C installed in the ramp section had the diameters of $1.7 \mathrm{~m}$ and $2.5 \mathrm{~m}$. Cambium vitality of the trees planted here was generally superior to those grown in the pots of the bridge section. More specifically, the diameter of Type A is $1.7 \mathrm{~m}$, securing some natural soil through excavation at the same level as the ground. The average electrical resistance of the trees planted here was $8.68 \mathrm{k} \Omega$, whereas the vitality of trees in Type B that has the same diameter but secured $45 \mathrm{~cm}$ of the aboveground part was $8.64 \mathrm{k} \Omega$, showing an extremely small difference. However, the average electrical resistance of Type $\mathrm{C}$, which has the diameter of $2.4 \mathrm{~m}$ and is $45 \mathrm{~cm}$ higher than the ground, was $4.78 \mathrm{k} \Omega$, showing that the relative vitality of trees that secured soil depth of roots as the pot

Table 3. relationships of planting pot Types, planting methods and vitality degrees

\begin{tabular}{|c|c|c|c|c|c|c|c|}
\hline \multirow[b]{2}{*}{ section } & \multicolumn{3}{|c|}{ category } & \multicolumn{2}{|c|}{ unit } & \multirow{2}{*}{$\begin{array}{c}\text { average viral } \\
\text { degree(k }(\mathrm{a})\end{array}$} & \multirow[b]{2}{*}{ planting method } \\
\hline & pots type & diameter(m) & height(m) & $\begin{array}{c}\text { total } \\
\text { quantity }\end{array}$ & $\begin{array}{c}\text { investigation } \\
\text { quantity }\end{array}$ & & \\
\hline \multirow{4}{*}{ ramp } & A & 1.7 & - & 8 & 7 & 8.68 & single \\
\hline & B & 1.7 & 0.45 & 64 & 64 & 8.64 & single \\
\hline & $\mathrm{C}$ & 2.5 & 0.45 & 4 & 4 & 4.78 & single \\
\hline & subtotal & \multicolumn{2}{|c|}{3 type } & 76 & 75 & 7.36 & \\
\hline \multirow{10}{*}{ bridge } & $\mathrm{D}$ & 1.24 & 0.95 & 25 & 10 & 13.10 & single/gathering \\
\hline & $\mathrm{E}$ & 1.7 & 0.95 & 119 & 110 & 10.28 & single/gathering \\
\hline & $\mathrm{F}$ & 2.5 & 0.45 & 1 & - & - & (measuring impossible) \\
\hline & G & 2.5 & 0.95 & 31 & 19 & 11.10 & single/ plural \\
\hline & $\mathrm{H}$ & 3.2 & 0.95 & 2 & 2 & 11.00 & gathering \\
\hline & $\mathrm{I}$ & 3.6 & 950 & 1 & - & - & (measuring exclusion) \\
\hline & $\mathrm{J}$ & 4.0 & 0.95 & 1 & 1 & 4.33 & gathering \\
\hline & K & 4.8 & 0.45 & 1 & 1 & 4.55 & gathering \\
\hline & $\mathrm{L}$ & 4.8 & 0.95 & 3 & 3 & 8.33 & gathering \\
\hline & subtotal & \multicolumn{2}{|c|}{9 type } & 184 & 146 & 8.95 & \\
\hline total & \multicolumn{3}{|c|}{12 type } & 260 & 221 & & \\
\hline
\end{tabular}


diameter and height was superior with discrimination.

The results of comparatively analyzing 146 pots in 9 types such as D, E, F, G, H, I, J, K, and L in the bridge section are as follows. Tree vitality in pots with a small diameter was relatively lower than large pots. There were 2 species exceeding the standard for relatively unhealthy trees (14k $\Omega$ ) in Type D with a diameter of $1.24 \mathrm{~m}, 3$ species in Type $\mathrm{E}$ with a diameter of $1.7 \mathrm{~m}$, and 2 species in Type $\mathrm{G}$ with a diameter of $2.5 \mathrm{~m}$, whereas none were measured in pots with a diameter of $3.2 \mathrm{~m}$ and above. Moreover, the mean in Type $\mathrm{J}$ with a diameter of $4 \mathrm{~m}$ was $4.33 \mathrm{k} \Omega$ and in Type $\mathrm{K}$ with a diameter of $4.5 \mathrm{~m}$ was $4.55 \mathrm{k} \Omega$, showing excellent vitality. However, the mean in Type L, a bigger pot, with a diameter of $4.8 \mathrm{~m}$ was $8.95 \mathrm{k} \Omega$, indicating that pot size does not have an absolute effect on tree vitality. In other words, factors such as tree type, planting method, lack of available water in the growth process, and competition over the growth foundation affect vitality. This is proved by the fact that the planting method of trees with higher measurements than the mean of Type L was group planting. The mean of Fraxinus rhynchophylla Hance (R8-R12, 17 trees in group planting) was $9.15 \mathrm{k} \Omega$ and the mean of Juniperus scopulorum (H1.5-H2.5 23 trees in group planting) was $12.40 \mathrm{k} \Omega$, suggesting the impact of insufficient growth foundation by group planting.

\section{Comparison of vitality according to the measurement direction}

This study used the Shigometer in four cardinal points (north, south, east, and west) to determine the relationship between urban locational conditions and tree vitality. The results were quite different from the previous study by $\mathrm{Ha}$ (2000) on general open land. While previous research on general open terrain showed excellent vitality in the east and south, this study showed slight, relatively fine vitality in the west and south compared to north and east. The above directions have good sunshine, lighting, and ventilation due to factors such as high-rise buildings near Seoullo 7017, thereby actively developing systemized cambium on the southwest than the northeast. In other words, the mean of tree vitality in each direction of the ramp section was west $8.06 \mathrm{k} \Omega$, south $8.11 \mathrm{k} \Omega$, north $8.14 \mathrm{k} \Omega$, and east
Table 4. comparison of vital degree with different directions

\begin{tabular}{cccccc}
\hline \multirow{2}{*}{ section } & \multirow{2}{*}{ quantity } & \multicolumn{4}{c}{ average vital degree by direction(k囚) } \\
\cline { 3 - 6 } & & East & West & South & North \\
\hline ramp & 75 & 8.44 & 8.06 & 8.11 & 8.14 \\
bridge & 376 & 10.86 & 10.19 & 10.07 & 10.17 \\
total & 451 & 9.65 & 9.13 & 9.09 & 9.16 \\
\hline
\end{tabular}

$8.44 \mathrm{k} \Omega$, thereby showing relatively superior vitality in the southwest $(8.09 \mathrm{k} \Omega)$ than the northeast $(8.29 \mathrm{k} \Omega)$. This result is also repeated in the bridge section, with west $10.19 \mathrm{k} \Omega$, south $10.07 \mathrm{k} \Omega$, north $10.17 \mathrm{k} \Omega$, and east $10.86 \mathrm{k} \Omega$, thereby showing relatively superior vitality in the southwest $(10.13 \mathrm{k} \Omega)$ than the northeast $(10.52 \mathrm{k} \Omega)$ (Table 4$)$.

\section{Conclusion}

The previous sections investigated and comparatively analyzed tree vitality of trees growing in the tree pots of Seoullo 7017, which transformed an overpass that was to be demolished into a 'sky garden'. As a result, 7 species including 5 species of Magnolia and Quercus dentata and Chamaecyparis pisifera 'Filifera Aurea' were already withered and thus could not be measured. In addition, as tree species exceeding $20 \mathrm{k} \Omega$, which is the vitality index for a dying tree, there were Stewartia pseudocamellia Maxim. with $21.68 \mathrm{k} \Omega$ and Thuja occidentalis $\mathrm{L}$. with $21.48 \mathrm{k} \Omega$. This is the result of the decision made to introduce the tree species in the order of the 'Korean alphabet' for display rather than considering the physiological and ecological aspects of plants to actualize the design concept of 'The Seoul Arboretum'. In this sense, extremely careful and thoughtful approach is needed to adopt and manage the relevant trees in a similar urban environment. We suggest planting suitable plants in the process of supplementary planting in 'Seoullo 7017' in the future considering the unique environment of the research site.

On the other hand, vitality was relatively superior in pots with a big diameter, trees planted individually than in groups, and trees in the ramp section than the bridge section. Vitality by the cambium direction of trees was relatively favorable in the southwest direction. This once again con- 
firms that stress from growth conditions of trees is reflected by tree vitality. Furthermore, there were many cases in which the trees that seemed to have no problem in growth conditions with the naked eye ended up showing negative measures observed. This is due to the inherent limitation of growth in tree pots on the artificial ground fully exposed in the city unlike the artificial ground of an apartment building. Therefore, to overcome this limitation, it is necessary to monitor the trees more closely, repair the watering and drainage system, and perform repotting, division, and soil improvement considering long-term maintenance.

This study has significance as the first study that measured the growth conditions of trees in Seoullo 7017, but is limited in that the data used were measured only once in summer and that it failed to conduct a complete enumeration due to the great quantity of trees. Moreover, the point in which the field investigation was conducted was when there was high moisture content in the soil due to the continuous rainy season. Thus, the results may turn out differently in soil environments of other seasons. However, despite these limitations, the results of obtaining means by measuring tree vitality in four directions when the trees show most active growth in the same soil conditions will contribute to determining adaptability of trees in the relevant environment more or less. Accordingly, to supplement the results of this study, a follow-up research must be conducted on measurements by season and temperature, soil moisture and root development state, and relevance with organic matter. Such follow-up research is expected to supplement and improve plantations in Seoullo 7017 using the overpass in the short term and contribute to technological development for establishment of a sustainable planting environment in the urban artificial ground in the long term.

\section{References}

Cha, B.J. and Na, Y.J. 1993. Comparison electrical resistance of street trees Seoul and Suwon with shigometa. J. Agric Sci. Res. 11(1)49-56.

Cha, D.W., D.S. Choi, J.W. Song, J.W. Choe, and C.H. Oh. 2020. Immigration plant characteristics of Seoullo 7017, as artificial foundation greening area, after com- pletion 1 year. J. Korea Soc. Environ. Restor. Technol. 23(1):15-36.

Choi, H.W. 2017. A study of the improvement of artificial planting ground in apartment complex: to the professional experience of landscape architect with special attension, Master's thesis, Hanyang University, Seoul, Korea.

Choung, E.H., 2018. A study on urban tourism through urban regeneration: Focusing on the case of Seoullo 7017. J. Korean Urban Geographical Soc. 21(1):53-64.

Gao, U.R. and B.J. Cha. 2009. Nondestructive Methods for the Detection of Internal Decay and the Vitality Measurement of Old-Giant Trees, Cultural Heritage, National Research Institute of Cultural Heritage. 42(1): 144-157. https://doi.org/10.22755/kjchs.2009.42.1.144

Ha, T.J. 2000. A sudy on the vitality of landscape woody plants based on changes in cambial electrical resistance and photosysthesis in Yonam college of agriculture. Master's thesis, Sangmyung University, Seoul, Korea

Hong, Y.S., Chung, D.Y, Choi, K.R, 2008. 4, A study on the inter-relational interpretation of street plant issues -Focus on central park road in Incheon metropolitan city. Journal of Korean Institute of Landscape Architecture. 36(1):80-89.

Kang, M.S., Lee, J.M., Ein, E.Y., Kim, O.G, and Kim, M.N. 2016. The study on the improvements plans for artificial ground landscaping of apartment housing(II), Land \& Housing Institute. http://www.riss.kr/link?id=M 14053782

Kim, H.J. 2018. A study on cognition and behavior of Seoullo 7017 visitors: Focusing on implementation of design concept, Master's thesis, Seoul University, Seoul, Korea.

Kim, J.H. 2019. An analysis of user satisfaction on Seoullo 7017. Master's thesis, Yonsei University, Seoul, Korea.

Kim, H.J. 1997. The diagnosis of deciduous pineal heart failure by shigometa, Tree Health Korean Soc. Arbor. Protection, 3:33-38.

Lee, J.S. 2019. Effect of 'Seoullo 7017' on city image and city preference of foreign tourists. Master's thesis, Kyunghee University, Seoul, Korea.

Park, C.I. and J.Y. Lee. 2019. Case study of green space planning in elevated linear parks. J. Environ. Sci. Int. 
28(2):267-276. https://doi.org/10.5322/JESI.2019.28.2.267

Park, S.J., Lee, W.S., and Mun, J.H. 2018, A study of visitor perception for Seoul-ro 7017 using IPA, J. Hosp. Tour. Stud. 20(3):14-22.

Park, S.J., J.O. Shin, and C. Jeong. 2018. A spatial structure analysis of the topological characteristic change on walking tourism: Focused on Seoullo 7017 project. J. Tour. Sci. 42(2):121-138.

Seoul Metropolitan City. 2017. Seoullo 7017 White Paper: Born again as Seoullo 7017 as human path on the old motorway Seoul station elevated road.-1,2,3 Seoullo operating institute. Retrieved from http://www.riss.kr/li nk?id=M14670327

The Korean Institute of Landscape Architecture. 2013. Landscape design standards. Retrieved from http://www. riss.kr/link?id=M13130466

Yeom, S.J. and J.Y. Lee. 2019. Changes of landscape perception in Seoullo 7017 with different planting design, based on landscape simulation. Environment Science International. Journal of Environment Science International. 28(11):951-958. https://doi.org/10.5322/JESI.2019.28.1 1.951 